\title{
Manufacturing Nanostructured and Microstructured Chitosan Prepared By Milling Shrimp Shell
}

Insaf Ould Brahim. ${ }^{* 1}$,Belmedani Mohamed $^{2}$,Hadoun Hocine ${ }^{3}$,Belgacem Ahmed $^{4}$,Haddad Ahmed. ${ }^{5}$

${ }^{1}$ Research Center in Industrial Technologies CRTI, P.O.Box 64, Cheraga 1601 Algiers.

2 Laboratory of Transfer Phenomena, Faculty of Mechanical and Processes Engineering, University of Sciences and Technology HouariBoumediene, BP n³2 El Alia babezzouar 16111 Algiers, Algeria;

${ }^{3}$ Nuclear Research Center of Algiers, 2 Bd Frantz Fanon, 16035, Algiers, Algeria.

${ }^{4}$ Laboratory of Transfer Phenomena, Faculty of Mechanical and Processes Engineering, University of Sciences and Technology HouariBoumediene, BP n³2 El Alia babezzouar 16111 Algiers, Algeria;

${ }^{5}$ Research Center in Industrial Technologies CRTI, P.O.Box 64, Cheraga 1601 Algiers.

\section{ARTICLE INFO}

\section{Keywords:}

Shrimp shell, Planetary

milling, chitosan, SEM,

FT-IR, XRD

\begin{abstract}
Nano-products are of great interest in the field of pharmaceutical, corrosion, medecine and engineering.

This research aimed to produce nano-chitosan. Nanocrystallite.

Shrimp shells have been prepared by using a high-energy planetary ball with an optimal rotational speed.

The raw material was subjected to standard chemical processing for chitin extraction, followed by deacetylation to obtain nanocrystallite chitosan, which is characterized by Scanning Electron Microscope SEM Fourier, Transform Infrared Spectrometry FT-IRand X-ray diffraction (XRD).
\end{abstract}

\section{Introduction}

In Algeria, shrimp are the most important crustacean sea food. Shrimp shel wastes which constitute approximately $50 \%$ of the total weight of shrimp become an environmental risk in Algeria due to the increase in the total production of shrimp (Toan, 2009). The utilization of shrimp shell wastes could be used in industry, corrosion, biotechnology and andbiomedecine.

Chitin, is a natural polysaccharide of major importance, The main commercial sources of chitin have been crab and shrimp shells. In industrial transformation, chitin is extracted from crustaceans by acid treatment dissolve the calcium carbonate followed by an alkaline extraction to solubilize proteins (Rinaudo, 2006).

Chitosan is a modified natural carbohydrate polymer derived from chitin which has been found in a wide range of natural sources such as crustaceans, insects and some algae (Hossain \& Iqbal, 2014). By partial deacetylation under alkaline conditions, one obtains chitosan, which is the most

$\square$ Corresponding Author E-Mail Address: iouldbrahim@gmail.com 
important chitin derivative in terms of applications (Kumari, Kumar Annamareddy, Abanti, \& Kumar Rath, 2017; Puvvada, Vankayalapati, \& Sukhavasi, 2012; Rinaudo, 2006).

The net cationicity, as well as the presence of multiple reactive functional groups in the molecule make chitosan a sought after biomolecule (Prashanth \& Tharanathan, 2007).

A serious challenge for the scientific community is to develop high-performance materials that meet the requirements related to environmental sustainability (Giuliani et al., 2018; Hossain \& Iqbal, 2014).

In this sense, we have synthesized a chitosan from shrimp shell carapace powder obtained by mechanical milling, which will find its use in the protection against corrosion (Chen, Yang, \& Jang, 2000; Giuliani et al., 2018).

\section{MATERIALS AND METHODS}

\subsection{Sample preparation Cleaning of shrimp shells}

The shrimp shells used in this study were obtained after the harvest of marine shrimp from the Algeria. The shells remained in the freezer at $0{ }^{\circ} \mathrm{C}$ until use. They were washed in running water to remove the excess organic material and dried at $80{ }^{\circ} \mathrm{C}$ for $24 \mathrm{~h}$. The dried samples were milled using a planetary mill. $20 \mathrm{~g}$ of shell powders were used for further analysis (Figure 1).

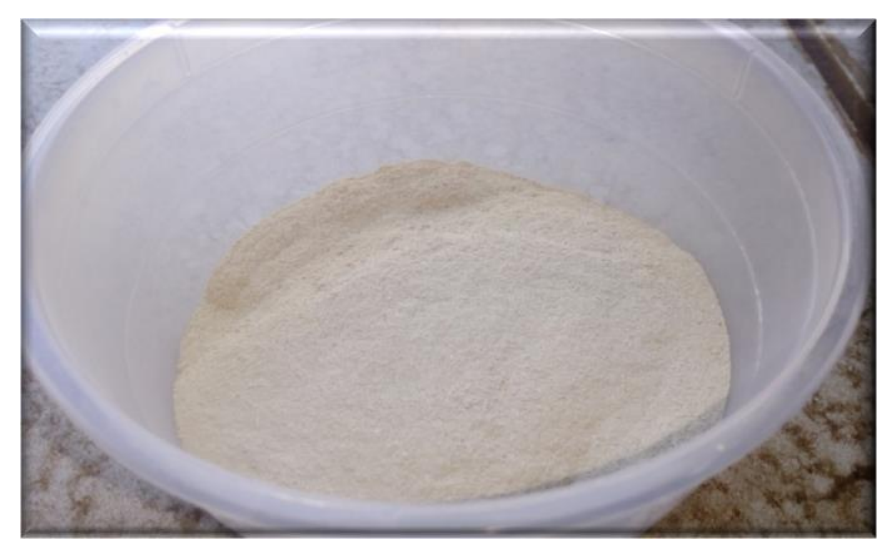

Figure 1: Fine powder obtain after shrimp shell grinding

\subsection{Milling (Planetary mills)}

At present planetary mills of high accelerations providing fast and efficient milling of various materials on industrial scale are commercially available in Algeria. 


\subsection{The principle of planetary mills performance}

Planetary mills are usually provided with 4 jars (Figure 2 ) rotating around the central axis and simultaneously around their own axes in the opposite direction . Material and milling bodies ( 8 balls with diametre equal for $1.9 \mathrm{~mm}$ ) are loaded into the jars. The treated material particles undergo multiple collisions with the grinding media and the jar walls. The potency of planetarymills isthat the results of the high mechanicalenergy of grinding media. High speed of moving edge bodies exerts high stress on the activated material. Velocity is between $250 \mathrm{rpm}$ and $300 \mathrm{rpm}$ during 1 hour.

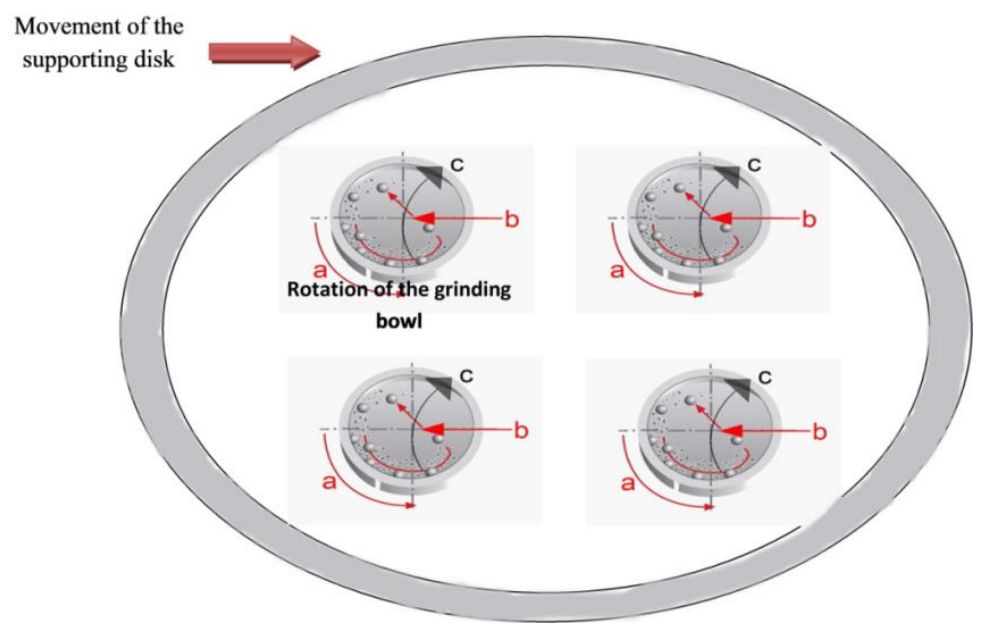

Figure 2: The principle of planetary mills performance

\subsection{Scanning Electron Microscopy (SEM)}

The SEM with accelerating voltage $30 \mathrm{kV}$ were used for characterization of precursor, chitine and chitosan.

Operating at $30 \mathrm{kV}$ where chitin have a uniform morphology with lamellar organization and specifically more crystalline appeared for chitin.

The structure and morphology of the chrimp carapace, chitin and chitosan were examined by SEM analysis. From Figure 3,4 and 5 respectively, the SEM micrographs showed that there is a difference in the roughness and surface morphology among the different types of shrimp carapace, chitin and chitosan.

The SEM analysis for shrimp carapace, showed non-smooth and non-homogenous surface. . For chitin, the SEM analysis showed a three-dimensional morphology and finally,SEM analysis for shrimp chitosan, showed that chitosan had a smooth and homogenous surface. 


\subsection{Elemental Composition (EDAX analysis)}

EDAX Analysis: Figure 6 illustrates the elemental composition of the powder of shrimp carapace, chitin and chitosan by dispersive energy analysis (EDAX).

EDAX analysis confirmed that the main peaks of the shrimp carapace, chitin and chitosan spectra, respectively, are $(\mathrm{C}),(\mathrm{O})$ and $(\mathrm{Ca})$, which are the main content of chitosan. The peak intensity for $(\mathrm{C}),(\mathrm{O})$ and $(\mathrm{Ca})$ was highest for chitosan (Fig $6 \mathrm{c}$ ), followed by chitin (Fig 6b), while the minimum intensity was for the chrimp carapace (figure 6a). Basically, no changes in chemical composition are observed regardless of the type of the materials used presents one of the EDS spectra (Figure 6).
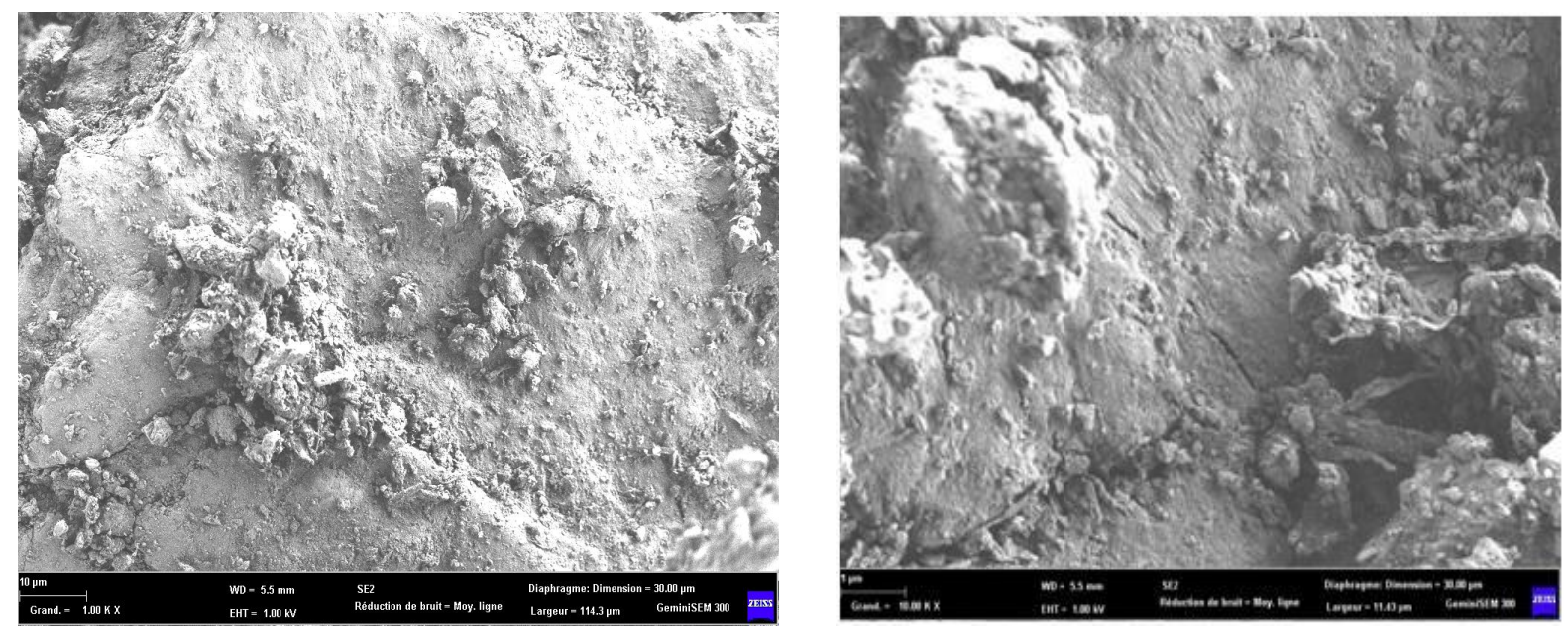

Figure 3: Shrimp carapace SEM 

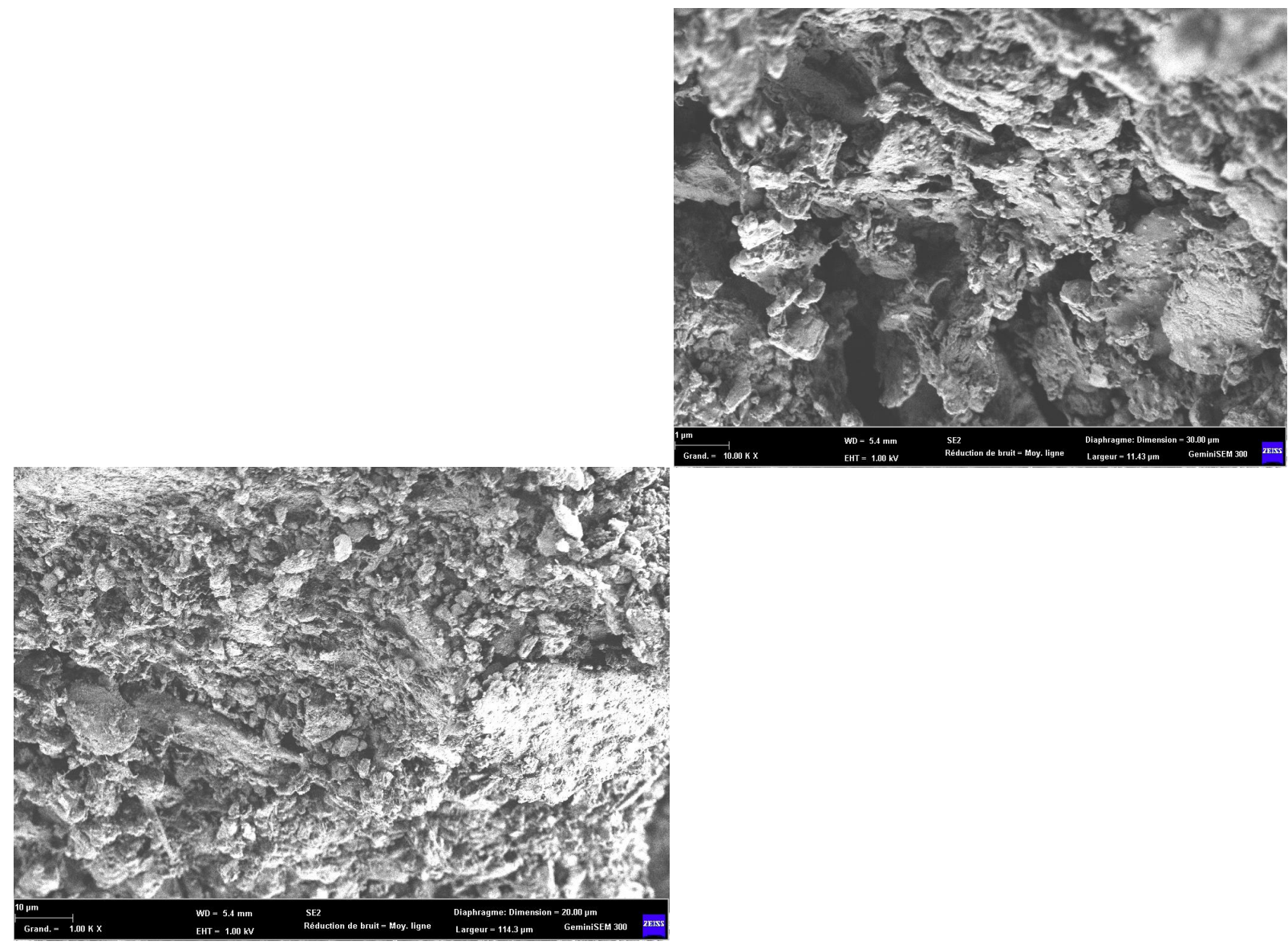

Figure 4: Chitin SEM
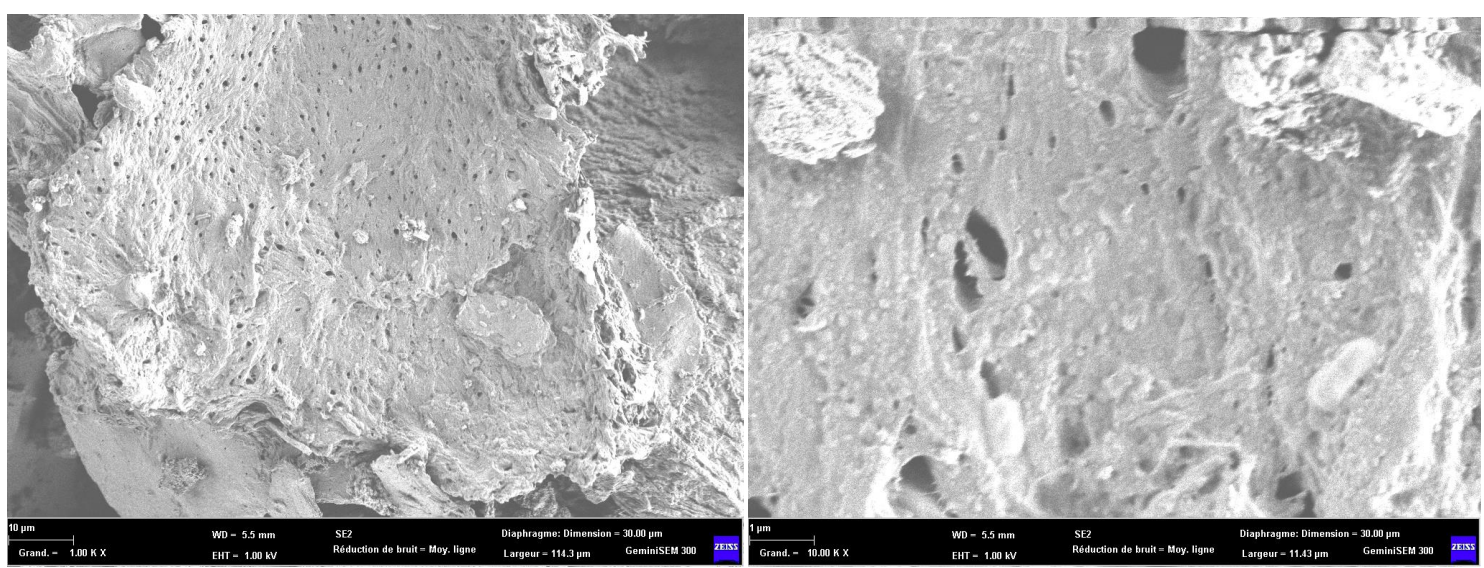

Figure 5: Chitosan SEM 

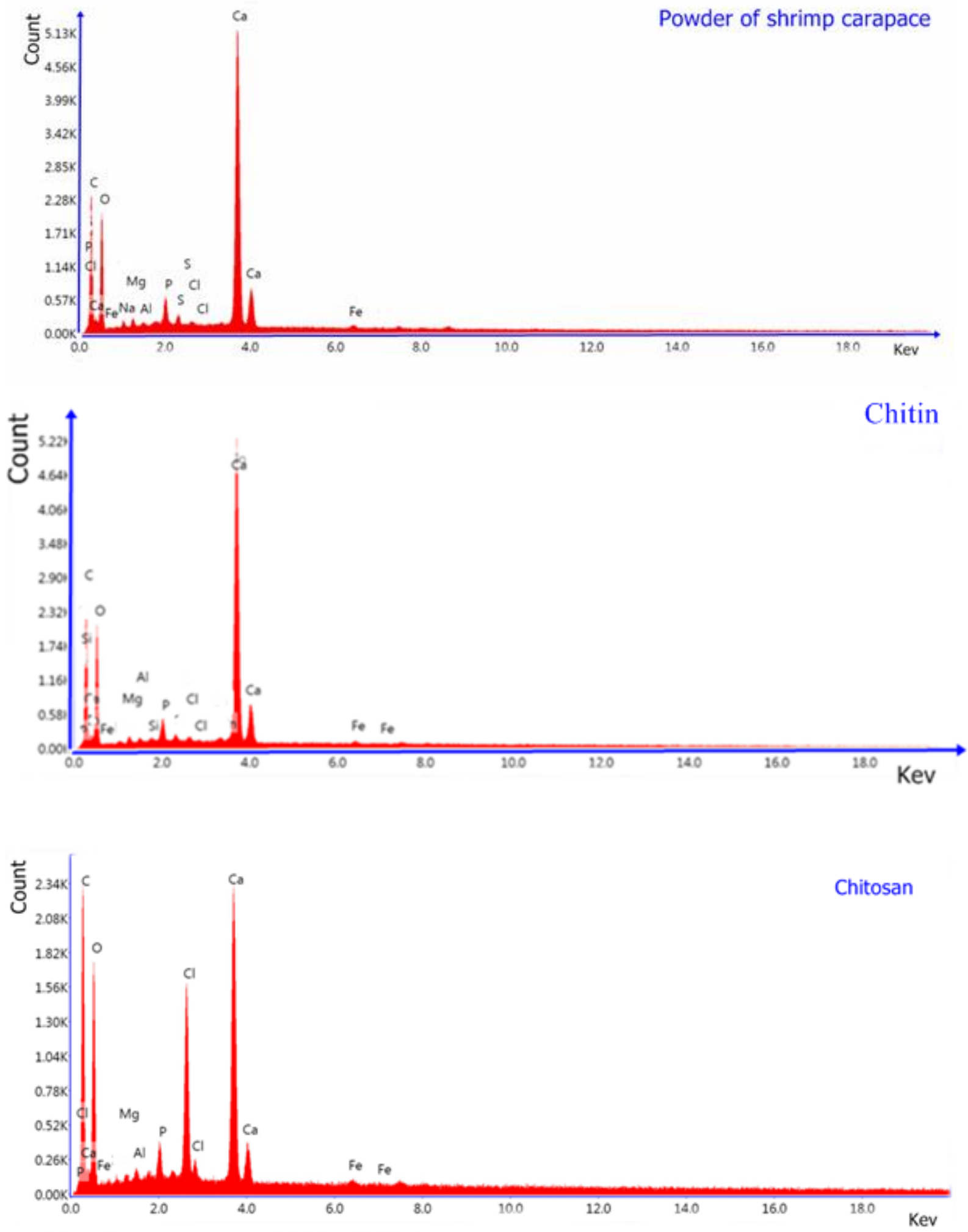
Figure 6:EDAX images of shrimp carapace, chitin and chitosan

\subsection{Fourier transforms infrared spectroscopy (FTIR analysis)}

Infra Red spectra of chitin and chitosan were performed using FTIR spectrophotometer (Agilent carry 630), in the range of 500-5000 $\mathrm{cm}^{-1}$, using ATR mode of operation

The structures of the shrimp carapace, chitin and chitosan were confirmed by FTIR in the range of $500-5000 \mathrm{~cm}^{-1}$ in the figures 7,8 and 9 .

Figures 7, 8 and 9 shows the infrared spectrum of the chitin in the spectrum field $2000-400 \mathrm{~cm}^{-1}$, $2000-400 \mathrm{~cm}^{-1}, 4000-400 \mathrm{~cm}^{-1}$, and $2000-400 \mathrm{~cm}^{-1}$, in the form transmittance vs. wave number. The bands are generally large due to the macromolecular character of the compound and because of the numerous intermolecular bindings of hydrogen, manifested even in the solid state of the sample (Negrea, Caunii, Sarac, \& Butnariu, 2015).

Figure 7 is the FT-IR spectrum for Shrimp carapace. The spectrum displays absorption bands at 662.4872, 707.5165, 872.4230, 1027.0133, 1065.9433, 1153.8934, 1416.4637, $1646.2032 \mathrm{~cm}^{-1}$.

Figure 8 is the FT-IR spectrum for Chitin. The spectrum displays absorption bands at 648.5568 , $708.1189,872.1218,1025.9592,1153.8934,1407.2018,1629.4867 \mathrm{~cm}^{-1}$ 'shows in a different manner than the previous figure, the infrared spectrums in a different spectrum: absorption vs. wave number, recommended for quantitative determinations. The absorption bands can be easily assigned to some molecular fragments: the dominant band with a maximum of $1629.4867 \mathrm{~cm}-1$ is owed to the valence's vibrations of the bindings $\mathrm{C}-\mathrm{H}$. The group of bands ranging from 648.5568 $\mathrm{cm}-1$ is characteristic to the amidic group.

Figure 9 is the FT-IR spectrum for Chitosan. The spectrum displays absorption bands at $1160.7457,1577.7558,1722.1054,2094.9898,2365.9183,2699.2703 \mathrm{~cm}-1$.

The band from $2699.2703 \mathrm{~cm}^{-1}$ is determined by $v(-\mathrm{C}=\mathrm{O})$ of the amide group CONHR of the chitosan. The bands $1577.7558 \mathrm{~cm}^{-1}$ (chitosan) is determined by $v(-\mathrm{C}=\mathrm{O})$ of the proton amide group. The band $1160.7457 \mathrm{~cm}^{-1}$ (chitosan) is determined by vas $(\mathrm{C}=\mathrm{O})$ oxygen bridges resulting from the deacetylation of the chitosan.

\subsection{X-ray Diffraction (XRD) analysis}

In order to determine crystal structure and morphology of powder shrimp carapce, chitin and chitosan, XRD analysis was used. Crystallinity of samples was evaluated by wide angle X-ray diffraction analysis using an BRUKER D8 DISCOVER difractometer operated using $\mathrm{Cu} \mathrm{K} \alpha$ as the radiation $(\lambda=0.15418 \mathrm{~nm})$. Diffraction patterns were recorded over a $2 \theta$ range of $5^{\circ}-70^{\circ}$ in continuous mode. 
Generally, Powder of shrimp shells are composed of carbohydrate as its main component, some mineral content (Calcium Carbonate, CaCO3) (Figure 10). (Samuthirapandian, Rameshkumar, \& Rosario Prince, 2009).

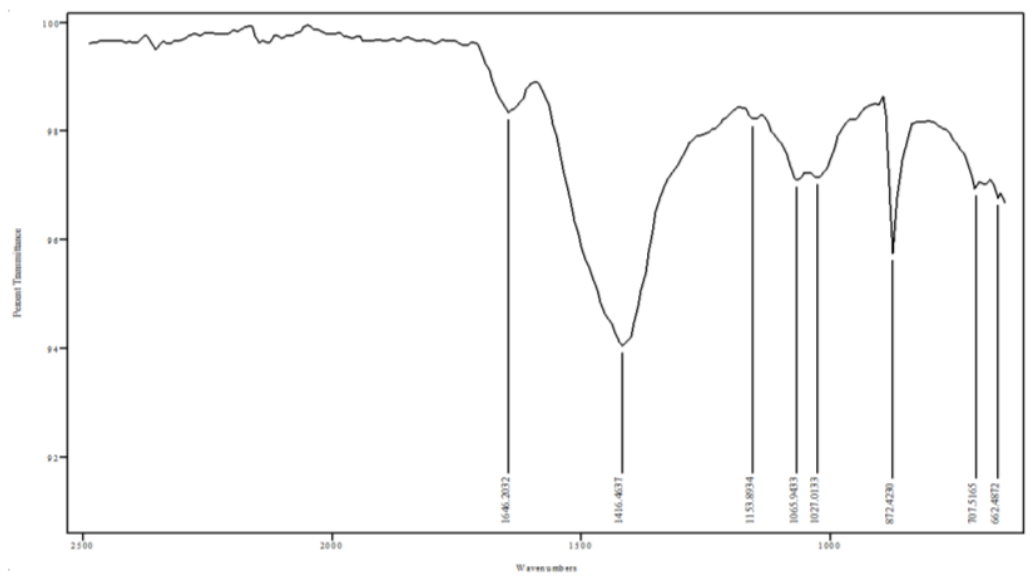

Figure 7: Shrimp carapace FTIR

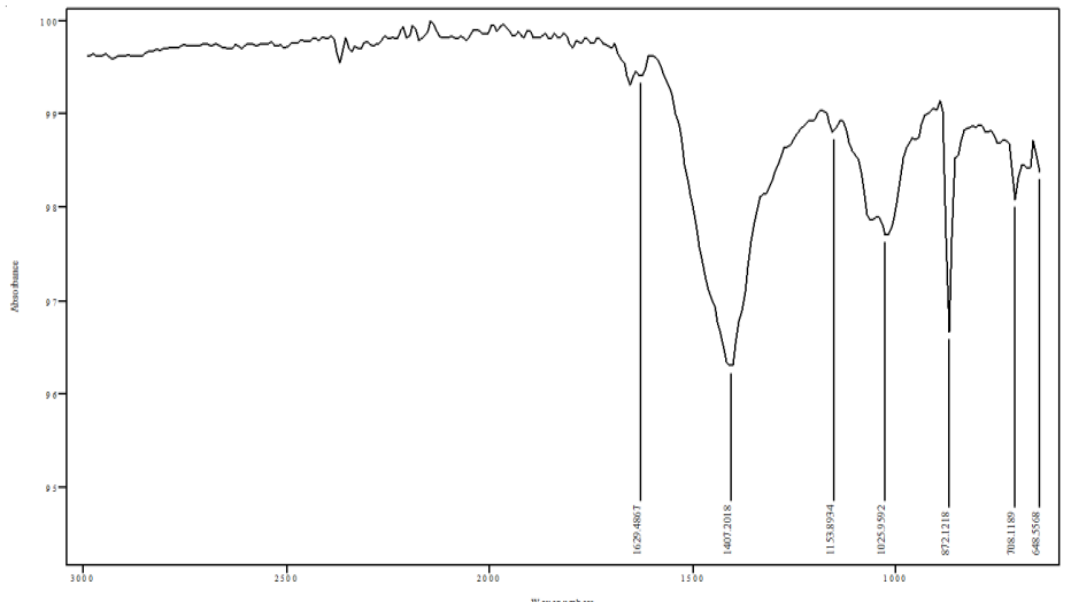

Figure 8: Chitin FTIR 
European Journal of Engineering Science and Technology, 2 (2):28-39, 2019

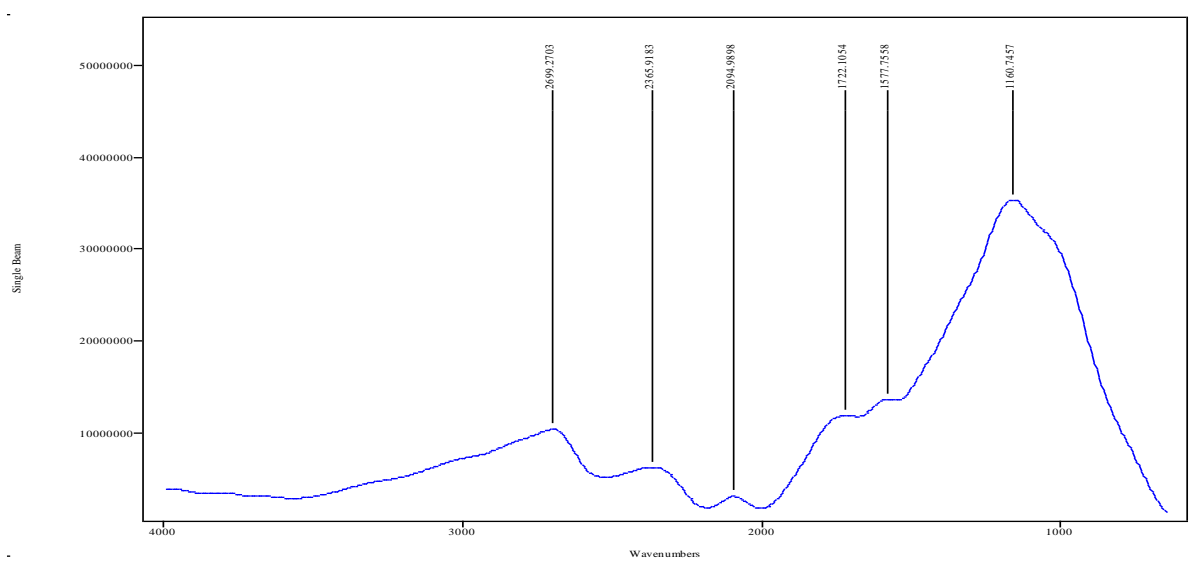

Figure 9: Chitosan FTIR 
The x-ray diffraction patterns of the powder of shrimp carapace, chitin and chitosan are represented in Figure 10.

Figures 10, 11 and 12 showed the XRD patterns of naked Shrimp carapace, chitin and chitosan respectively. The particles sizes can be evaluated using Debye-Sherrer equation from the XRD date given by the following equation

$$
D=\frac{k \lambda}{\beta \cos \theta}
$$

Where,

$\mathrm{k}$ is the sherrer constant, $\mathrm{k}=0.89$

$\lambda$ is the $\mathrm{X}$-ray wavelengh $\lambda, \lambda=0.15406 \mathrm{~nm}$

$\beta$ is the peak width of half-maximum and,

$\theta$ is thee Bragg Diffraction angle.

The crystallite size of the nano chitosan was found about $71.65 \mathrm{~nm}$.

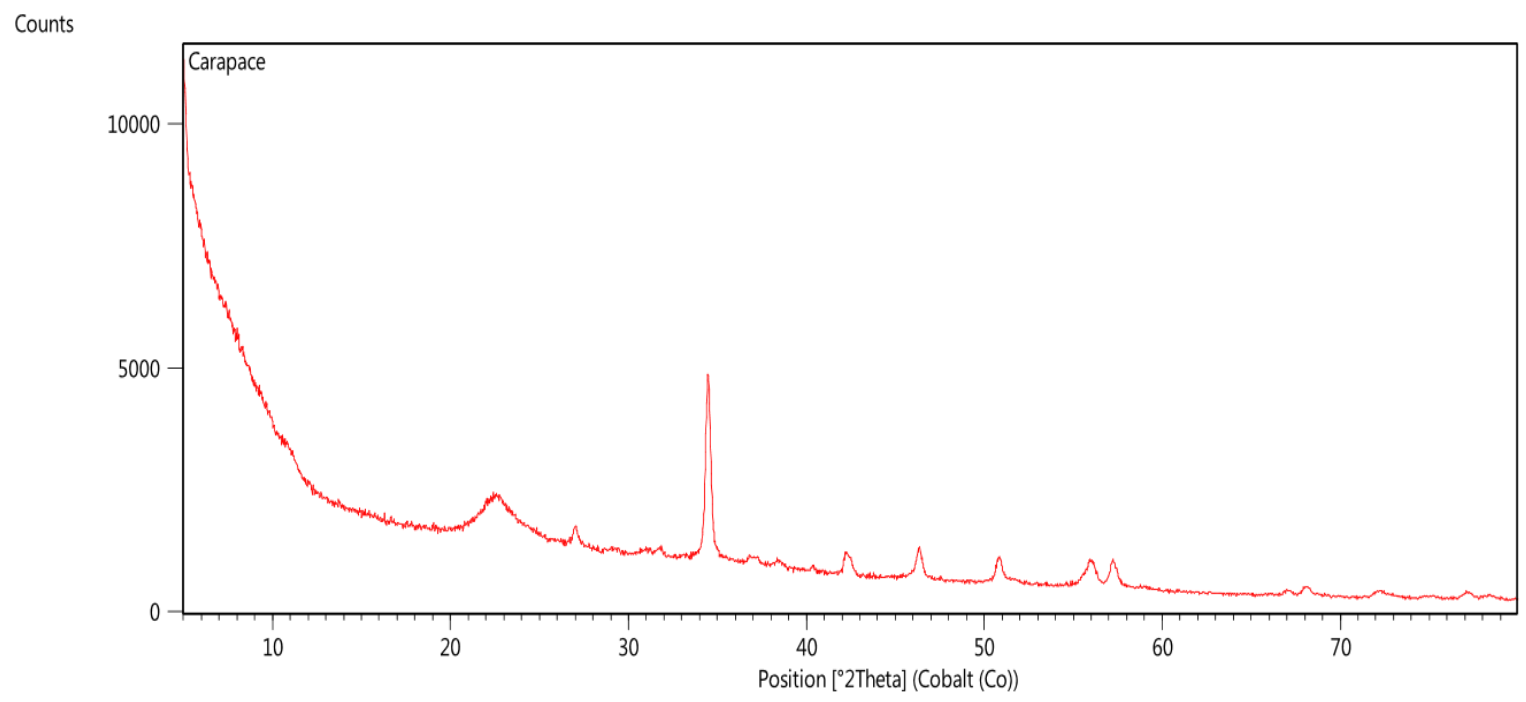

Figure 10:Shrimp carapace XRD 


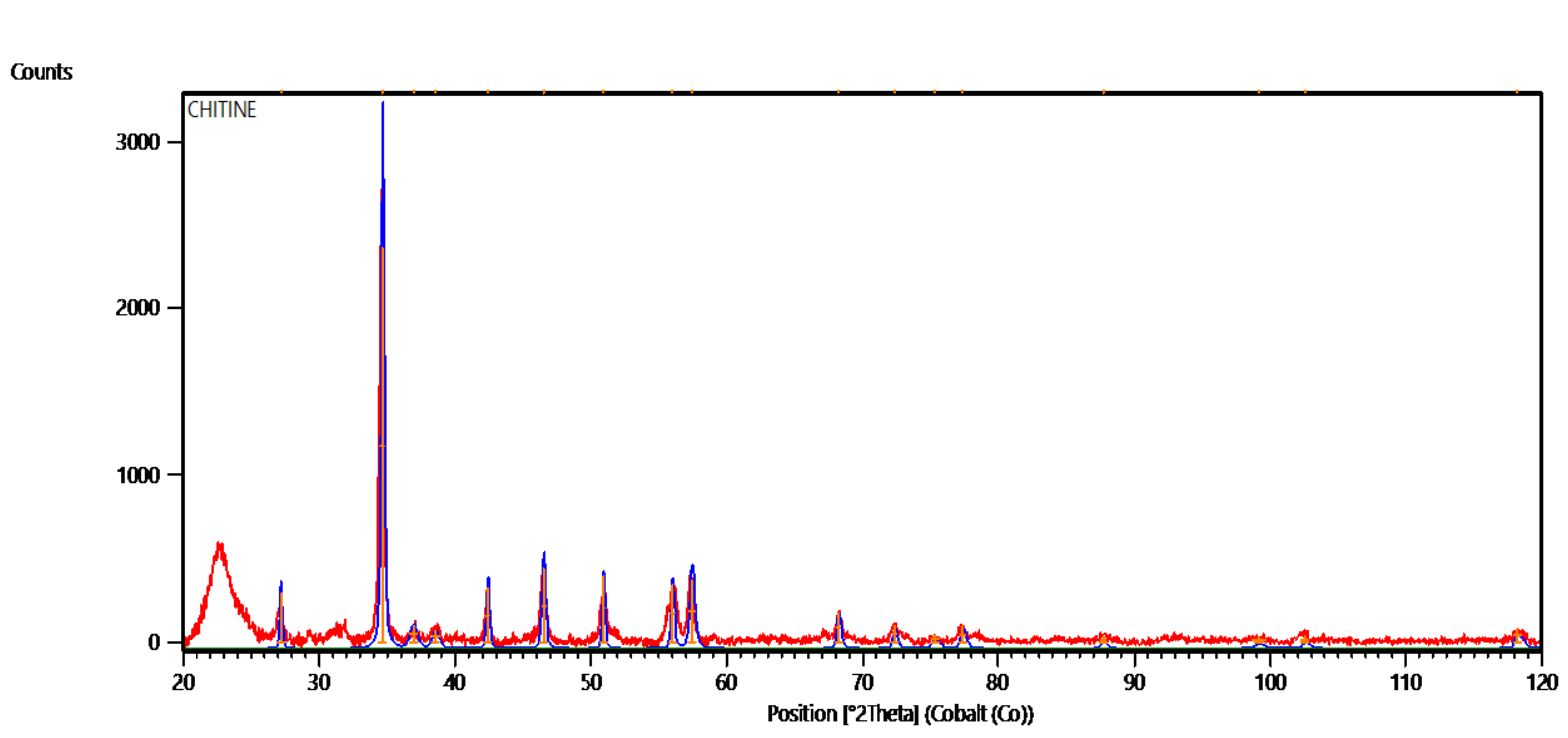

Figure 11: Chitin XRD

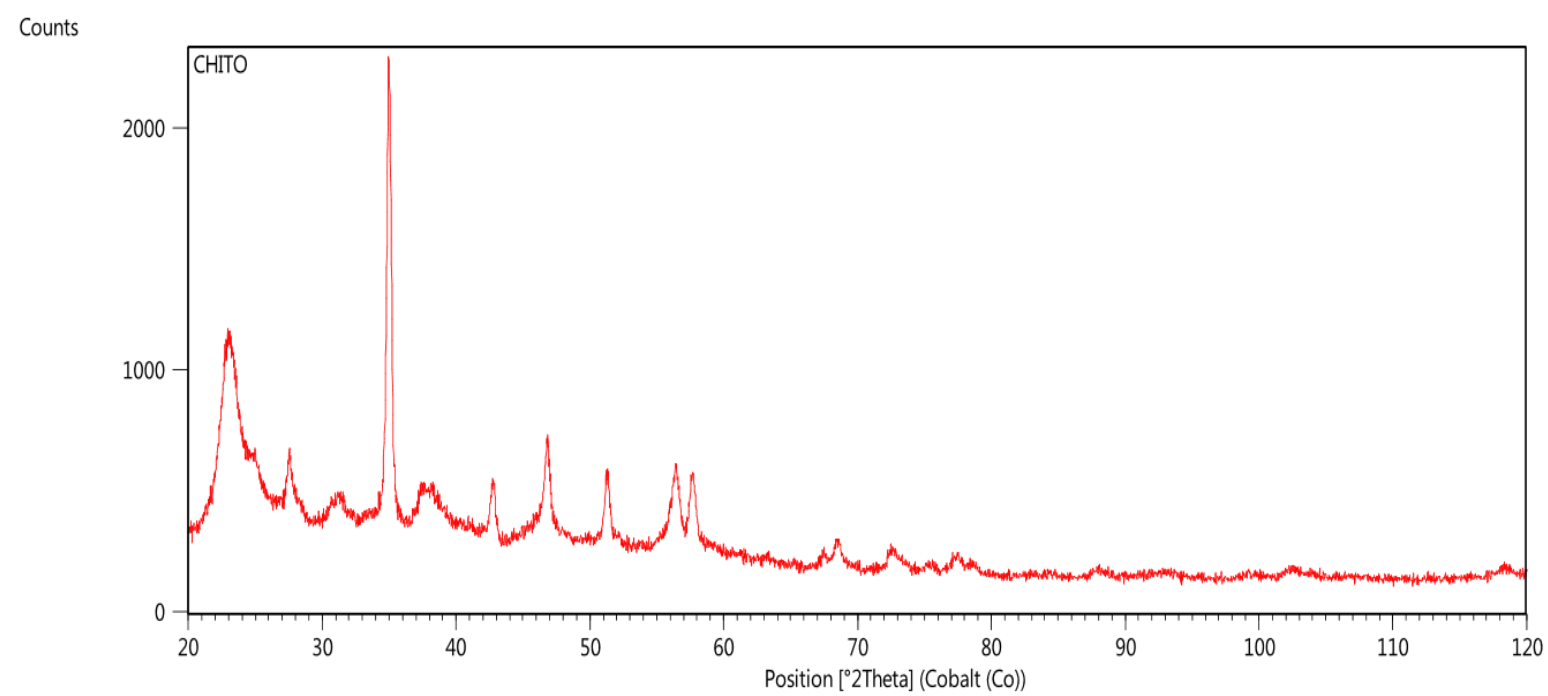

Figure 12: Chitosan XRD

\section{Conclusion}

This study has demonstrated that chitin and chitosan can be effectively extracted from shrimp shells wastes obtained using a planetary mill, following demineralization and deproteination.

Chitosan, the most important derivative of chitin, was successfully obtained by partial deacetylation of chitin under alkaline conditions.

EDAX analysis showed that the main peaks of the shrimp carapace, chitin and chitosan spectra, respectively, are $(\mathrm{C}),(\mathrm{O})$ and $(\mathrm{Ca})$.

Xray analysis showed that crystallite size of the nano chitosan was found about $100 \mathrm{~nm}$. 
The powder of shrimp carapace was successfully transformed to biopolymer. The present study confirmed that the shrimp carapace can be transform into chitosan after milling by planetary mill, and this method is an effective in solving one of the greatest environmental and economic problems in Algeria.

\section{Knowledgment}

This paper is an output of the science project Nanomaterials and Corrosion phenomena

\section{References}

[1] N.V. Toan, Production of chitin and chitosan from partially autolyzed shrimp shell materials, The open biomaterials journal, 1 (2009).

[2] M. Rinaudo, Chitin and chitosan: Properties and applications, Progress in Polymer Science, 31 (2006) 603-632.

[3] M.S. Hossain, A. Iqbal, Production and characterization of chitosan from shrimp waste, J. Bangladesh Agril. Univ, 12 (2014) 153-160.

[4] S. Kumari, S.H. Kumar Annamareddy, S. Abanti, P. Kumar Rath, Physicochemical properties and characterization of chitosan synthesized from fish scales, crab and shrimp shells, International journal of biological macromolecules, 104 (2017) 1697-1705.

[5] Y.S. Puvvada, S. Vankayalapati, S. Sukhavasi, Extraction of chitin from chitosan from exoskeleton of shrimp for application in the pharmaceutical industry, International Current Pharmaceutical Journal, 1 (2012) 258-263.

[6] H. Prashanth, R.N. Tharanathan, Chitin/chitosan: Modifications and their unlimited application potential—An overview, 2007.

[7] C. Giuliani, M. Pascucci, C. Riccucci, E. Messina, M. Salzano de Luna, M. Lavorgna, G.M. Ingo, G. Di Carlo, Chitosan-based coatings for corrosion protection of copper-based alloys: A promising more sustainable approach for cultural heritage applications, Progress in Organic Coatings, 122 (2018) 138-146.

[8] S. Chen, J. Yang, B.Z. Jang, High-energy planetary ball milling apparatus and method for the preparation of nanometer-sized powders, in, Google Patents, 2000.

[9] P. Negrea, A. Caunii, I. Sarac, M. Butnariu, the study of infrared spectrum of chitin and chitosan extract as potential sources of biomass, Digest Journal of Nanomaterials \& Biostructures (DJNB), 10 (2015).

[10] R. Samuthirapandian, G. Rameshkumar, A. Rosario Prince, Biochemical Composition of Shell and Flesh of the Indian White Shrimp Penaeusindicus (H.milne Edwards 1837), 2009. 
Chen, S., Yang, J., \& Jang, B. Z. (2000). High-energy planetary ball milling apparatus and method for the preparation of nanometer-sized powders: Google Patents.

Giuliani, C., Pascucci, M., Riccucci, C., Messina, E., Salzano de Luna, M., Lavorgna, M., . . Di Carlo, G. (2018). Chitosan-based coatings for corrosion protection of copper-based alloys: A promising more sustainable approach for cultural heritage applications. Progress in Organic Coatings, 122, 138-146. doi: https://doi.org/10.1016/j.porgcoat.2018.05.002

Hossain, M. S., \& Iqbal, A. (2014). Production and characterization of chitosan from shrimp waste. J. Bangladesh Agril. Univ, 12(1), 153-160.

Kumari, S., Kumar Annamareddy, S. H., Abanti, S., \& Kumar Rath, P. (2017). Physicochemical properties and characterization of chitosan synthesized from fish scales, crab and shrimp shells. International journal of biological macromolecules, 104, 1697-1705. doi: https://doi.org/10.1016/j.ijbiomac.2017.04.119

Negrea, P., Caunii, A., Sarac, I., \& Butnariu, M. (2015). THE STUDY OF INFRARED SPECTRUM OF CHITIN AND CHITOSAN EXTRACT AS POTENTIAL SOURCES OF BIOMASS. Digest Journal of Nanomaterials \& Biostructures (DJNB), 10(4).

Prashanth, H., \& Tharanathan, R. N. (2007). Chitin/chitosan: Modifications and their unlimited application potential-An overview (Vol. 18).

Puvvada, Y. S., Vankayalapati, S., \& Sukhavasi, S. (2012). Extraction of chitin from chitosan from exoskeleton of shrimp for application in the pharmaceutical industry. International Current Pharmaceutical Journal, 1(9), 258-263.

Rinaudo, M. (2006). Chitin and chitosan: Properties and applications. Progress in Polymer Science, 31(7), 603-632. doi: https://doi.org/10.1016/j.progpolymsci.2006.06.001

Samuthirapandian, R., Rameshkumar, G., \& Rosario Prince, A. (2009). Biochemical Composition of Shell and Flesh of the Indian White Shrimp Penaeus indicus (H.milne Edwards 1837) (Vol. 4).

Toan, N. V. (2009). Production of chitin and chitosan from partially autolyzed shrimp shell materials. The open biomaterials journal, 1(1). 